\title{
(2) OPEN ACCESS \\ Genetic background of high blood pressure is associated with reduced mortality in premature neonates
}

\author{
Wolfgang Göpel, ${ }^{1}$ Mirja Müller, ${ }^{1}$ Heike Rabe $\mathbb{C}^{1},{ }^{2}$ Johannes Borgmann, ${ }^{1}$ \\ Tanja K Rausch, ${ }^{3}$ Kirstin Faust, ${ }_{1}^{1}$ Angela Kribs, ${ }^{4}$ Jörg Dötsch, ${ }^{5}$ David Ellinghaus, ${ }^{6}$ \\ Christoph Härtel, ${ }^{1}$ Claudia Roll, ${ }^{7}$ Miklos Szabo, ${ }^{8}$ Peter Nürnberg, ${ }_{1}^{9}$ Andre Franke, ${ }^{6}$ \\ Inke R König, ${ }^{3}$ Mark A Turner [1] , ${ }^{10}$ Egbert Herting ${ }^{1}$
}

\begin{abstract}
- Additional material is published online only. To view, please visit the journal online (http://dx.doi.org/10.1136/ archdischild-2019-317131).

For numbered affiliations see end of article.
\end{abstract}

\section{Correspondence to} Professor Wolfgang Göpel, Paediatrics, University of Lübeck, Lübeck 23538, Germany; wolfgang.goepel@uksh.de

Received 27 February 2019 Revised 7 May 2019 Accepted 28 May 2019 Published Online First 14 June 2019

\section{Check for updates}

(C) Author(s) (or their employer(s)) 2020. Re-use permitted under CC BY-NC. No commercial re-use. See rights and permissions. Published by BMJ.

To cite: Göpel W, Müller M, Rabe $\mathrm{H}_{\text {, et al. Arch Dis Child }}$ Fetal Neonatal Ed

2020;105:F184-F189.

\section{ABSTRACT}

Objective The aim of our study was to determine if a genetic background of high blood pressure is a survival factor in preterm infants.

Design Prospective cohort study.

Setting Patients were enrolled in 53 neonatal intensive care units.

Patients Preterm infants with a birth weight below $1500 \mathrm{~g}$.

Exposures Genetic score blood pressure estimates were calculated based on adult data. We compared infants with high genetic blood pressure estimates ( $>75$ th percentile of the genetic score) to infants with low genetic blood pressure estimates $(<25$ th percentile of the genetic score).

Main outcome measures Lowest blood pressure on the first day of life and mortality.

Results 5580 preterm infants with a mean gestational age of $28.1 \pm 2.2$ weeks and a mean birth weight of $1022 \pm 299 \mathrm{~g}$ were genotyped and analysed. Infants with low genetic blood pressure estimates had significantly lower blood pressure if compared with infants with high genetic blood pressure estimates $(27.3 \pm 6.2 \mathrm{vs}$ $27.9 \pm 6.4, p=0.009$, t-test). Other risk factors for low blood pressure included low gestational age $(-1.26 \mathrm{~mm}$ $\mathrm{Hg} /$ week) and mechanical ventilation $(-2.24 \mathrm{~mm} \mathrm{Hg}$, $p<0.001$ for both variables, linear regression analysis). Mortality was significantly reduced in infants with high genetic blood pressure estimates (28-day mortality: $21 / 1395,1.5 \%$ vs $44 / 1395,3.2 \%, p=0.005$, Fisher's exact test). This survival advantage was independent of treatment with catecholamines.

Conclusions Our study provides first evidence that a genetic background of high blood pressure may be beneficial with regard to survival of preterm infants.

\section{INTRODUCTION}

In all neonates blood pressure gradually increases during the first weeks of life. In preterm infants, blood pressure at birth is closely related to gestational age. ${ }^{1}$ Considerable uncertainty exists with regard to the relevance and treatment of low blood pressure. $^{2}$ In observational studies, low blood pressure is associated with death and other adverse outcomes like intraventricular haemorrhage, periventricular leukomalacia and bronchopulmonary dysplasia. ${ }^{3-6}$ However, most adverse

\section{What is already known on this topic?}

- No large-scale randomised trials concerning the treatment of low blood pressure in preterm infants have been published so far.

- Observational data in preterm infants are conflicting since low blood pressure is associated with a number of risk factors for adverse outcomes.

\section{What this study adds?}

- A genetic background of high blood pressure was associated with reduced mortality in preterm infants which was not altered by catecholamine therapy.

- Our data give the first evidence that genetic predisposition for high blood pressure is evolutionary beneficial and that current concepts of therapy are not sufficient.

short-term and long-term outcomes are reported in infants with low blood pressure who were treated with catecholamines. ${ }^{3}$ 6-8 These data raise the question whether arterial hypotension itself or the treatment of the condition with catecholamines is harmful. Many neonatologists therefore consider low arterial blood pressure not as an indication for urgent medical intervention, if a baby is otherwise stable. ${ }^{8-10}$ However, experience in adults, children, and several observational studies in preterm infants ${ }^{3-6} 1112$ promote a different approach with early volume replacement and intravenous application of catecholamines to prevent prolonged hypotension. As of yet, no large-scale randomised controlled trials of catecholamine treatment in preterm infants have been published. ${ }^{1314}$

In adults, blood pressure is in part a heritable trait and the predisposition for high or low blood pressure is randomly inherited at the time of fertilisation. Therefore, genetically determined blood pressure scores are independent from main confounders of outcome in preterm infants. We genotyped a large number of preterm infants for validated genetic polymorphisms influencing blood pressure in adults. ${ }^{15}$ The aim of our study was to 
determine if a genetic background of high blood pressure is a survival factor in preterm infants.

\section{METHODS}

\section{Study design and participants}

The German Neonatal Network (GNN) collected data in a prospective cohort study. Preterm infants with a birth weight below $1500 \mathrm{~g}$ who were admitted to one of the participating study centres were eligible. After informed parental consent, a predefined clinical data set was recorded for each patient. Data quality was ensured by regular onsite monitoring of participating centres. All data were entered in a database by health record administrators at the main GNN office at the University of Lübeck, Germany.

Infants were selected for genetic analysis if chip genotyping data were available and if their maternal descent was European. In multiples, only one infant per twin pair or triplet was selected for the genetic analysis by using the random generator of the ' $R$ ' statistical computing software. We furthermore excluded infants without recorded lowest blood pressure data on the first day of life and infants with a gestational age above $31+6$ weeks at birth. All selected infants were enrolled in the GNN between 2009 and 2016. Details of patient selection are given in online supplementary figure 1 .

\section{Exposures}

Published risk factors for low blood pressure in preterm infants include low gestational age, lack of antenatal administration of steroids, mechanical ventilation, multiple birth, emergency caesarean section and 5 min APGAR score below 7. ${ }^{416}$ We analysed the effect of these factors on the lowest mean blood pressure levels on day 1 in a linear regression analysis and included the individual gsBP of each infant as a continuous covariate.

Delayed cord clamping and cord milking is also associated with higher blood pressure ${ }^{16}$ and reduces mortality in preterm infants, ${ }^{17}$ but was not recorded in the GNN on an individual basis. Therefore, the effect of late cord clamping and cord milking could not be assessed in our study. However, due to sitespecific questionnaires we know that about $90 \%$ of all newborn intensive care units participating in the GNN do either late cord clamping or cord milking or both.

Birth weight, sex and small for gestational age status (defined as birth weight $<10$ th percentile) ${ }^{18}$ are reported as descriptive data.

\section{Genotyping}

Umbilical cord tissue of participating infants was collected after birth and stored at $-20^{\circ} \mathrm{C}$ until transfer to the University of Lübeck. DNA was extracted by standard procedures (Gentra Puregene Tissue Kit, Qiagen, Hilden, Germany). Chip genotyping was done by the Cologne Center for Genomics using 'Axiom CEU' (Affymetrix, Santa Clara, California, USA) or the Institute of Clinical Molecular Biology Kiel using 'Global Screening Array (GSA)' (Illumina, San Diego, California, USA). After chip genotyping of approximately 500000 single nucleotide polymorphisms (SNPs) per infant, additional SNPs were imputed. After imputation and quality control, validated SNPs associated with blood pressure in European adults $(n=267)$ were selected. ${ }^{15}$ Fourteen SNPs were not available in the Axiom-CEU datasets and 16 in the GSA datasets. Two hundred thirty-seven SNPs were available in both datasets and used for this analysis. Many SNPs associated with blood pressure in adults are located close to genes which are expressed in venous or arterial vessels. Expression in cardiopulmonary tissue was less frequently observed. ${ }^{15}$ Details of selected and excluded SNPs are given in online supplementary table 1 . Genetic score blood pressure (gsBP) was calculated based on adult beta estimates according to reference 15 by: gsBP $=($ gsBP diastolic + gsBP systolic $) / 2$. An example how gsBP scores in preterm infants were calculated is given in online supplementary table 1 .

If groups of adults are compared, differences in cumulated beta estimates are closely linked to differences in mean blood pressure (in $\mathrm{mm} \mathrm{Hg}$ ). ${ }^{15}$ Since mean blood pressure in preterm infants is much lower than in adults, we expected that adult beta estimates will not reflect differences in preterm infants (in $\mathrm{mm}$ $\mathrm{Hg}$ ). Therefore, we compared infants with low genetic beta estimates (gsBP $<$ P25) with infants with high genetic beta estimates (gsBP $>$ P75). Data of infants with intermediate beta estimates (P25-P75) are given as descriptive data only.

\section{Outcomes}

The only blood pressure recorded in the GNN dataset is the lowest mean blood pressure on the first day of life. ${ }^{4}$ We compared measured lowest mean blood pressure on the first day of life between infants with low and high genetic beta estimates for blood pressure.

According to our previous publication, ${ }^{4}$ we selected all-cause mortality during the stay in the hospital as the primary end point of our analysis. We also analysed neonatal mortality (within the first 28 days of life). Common complications of premature birth were analysed as secondary end points. Intraventricular haemorrhage (IVH) was defined as localised bleeding in the germinal matrix (grade I), blood filling up to $50 \%$ of a ventricle (grade II), blood filling $>50 \%$ of a ventricle (grade III) and IVH of any stage with additional periventricular haemorrhagic infarction (grade IV) according to Papile et al. ${ }^{19}$ Periventricular leukomalacia (PVL) was defined as parenchymal cystic lesions in the periventricular region. Bronchopulmonary dysplasia (BPD) was defined as need of oxygen or respiratory support (continuous positive airway pressure or mechanical ventilation) at $36+0$ weeks postmenstrual gestational age. Sepsis was defined as blood culture-proven sepsis with at least two clinical signs. Necrotising enterocolitis was defined as necrotising intestinal inflammation requiring surgery. Retinopathy of prematurity (ROP) was defined as ROP requiring treatment. Persistent ductus arteriosus (PDA) was defined as surgical closure of PDA. Missing data were not imputed.

\section{Statistics}

Data were analysed with SPSS statistics V.25.0 (IBM, New York, USA). The type I error level was set to 0.05 . All $\mathrm{p}$ values given are two-sided. To test for group differences, we compared infants with low genetic blood pressure estimates $(<\mathrm{P} 25)$ and infants with high genetic blood pressure estimates by Fisher's exact test and t-test. To estimate the direct effect of the adult genetic risk score beta estimates on preterm infant blood pressure, we entered crude genetic risk scores beta estimates of preterm infants in a linear regression model including gestational age, lack of antenatal administration of steroids, mechanical ventilation, multiple birth, emergency caesarean section and $5 \mathrm{~min}$ APGAR score below 7 .

\section{RESULTS}

A total number of 5580 infants were available for gsBP analysis (see online supplementary figure 1). Preterm infant effect allele frequencies for individual SNPs are given in online supplementary 
Table 1 Characteristics of preterm infants by genetic score blood pressure (gsBP)

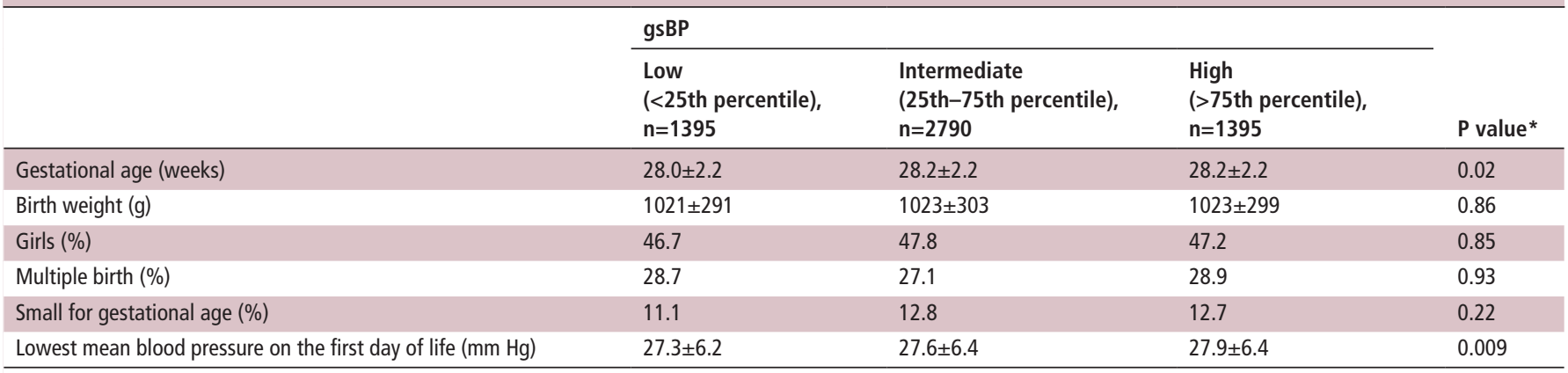

*Two-sided p value comparing groups with low vs high gsBP. Gestational age, birth weight and mean blood pressure are given as mean \pm SD and compared with t-test. Fisher's exact test was used to compare all other variables.

table 1 and were very similar to adults. Cumulated beta coefficients and thresholds for gsBP quartiles are given in online supplementary figure 2. Clinical data for infants with different gsBP are given in table 1 . Mean gestational age was about 1 day higher in infants with high gsBP if compared with infants with low gsBP. Infants with high gsBP had significantly higher mean blood pressure on the first day of life. However, the total effect of the genetic score on minimal blood pressure during the first 24 hours in preterm infants was $<1 \mathrm{~mm} \mathrm{Hg}$.

To estimate the effects of clinical factors influencing blood pressure on the first day of life, we conducted a linear regression analysis (table 2). Gestational age and mechanical ventilation were the strongest predictors of blood pressure on the first day of life. Antenatal treatment with steroids increased blood pressure. Multiple birth and emergency caesarean section were associated with reduced blood pressure. Blood pressure on the first day of life in preterm infants with different clinical risk profiles is given in online supplementary table S2. Infants who were mechanically ventilated with one or more additional risk factors had lowest mean blood pressure values on the first day of life which were $24.3 \pm 5.7 \mathrm{~mm} \mathrm{Hg}$, although mean gestational age in this group was $27.1 \pm 2.2$ weeks. More than $40 \%$ of these infants were treated with catecholamines during their stay in the hospital.

Adult gsBP was significantly associated with blood pressure in preterm infants on the first day of life, but the effect size was small. One $\mathrm{mm} \mathrm{Hg}$ increase in adult gsBP was associated with a $0.06 \mathrm{~mm} \mathrm{Hg}$ increased blood pressure in preterm infants on the first day of life (table 2). Treatment with catecholamines stratified to gsBP is given in online supplementary table S3. Infants with high gsBP received less epinephrine. No other differences were observed.

A significantly lower mortality rate was observed in infants with high gsBP. Forty of 1395 (2.9\%) infants with high gsBP died compared with 63 of 1395 (4.5\%) infants with low gsBP ( $\mathrm{p}=0.027$, OR $0.62,95 \%$ CI 0.42 to 0.93 , Fisher's exact test). This was in particular due to a reduced mortality within the first 28 days of life (high gsBP: $1.5 \%$ vs low gsBP $3.2 \%, p=0.005$, OR $0.47,95 \%$ CI 0.28 to 0.79 , Fisher's exact test). Mortality stratified for catecholamine treatment and gsBP is given in figure 1 . Infants receiving catecholamines $(n=1096)$ if compared with infants who were not treated with catecholamines had a 20 -fold increased mortality within 28 days $(9.9 \%$ vs $0.5 \%)$, and during the stay in the hospital $(15.8 \%$ vs $0.8 \%)$. However, if stratified for gsBP, infants with a predisposition for high gsBP had significantly lower 28 days mortality rates even if treated with catecholamines (figure 1). In a logistic regression analysis with 28-day mortality as dependent variable, lower measured blood pressure on the first day of life and a genetic background of low blood pressure and treatment with catecholamines were associated with higher mortality rates (table 3).

Descriptive data for complications of premature birth are given in table 4. Infants with high gsBP had lower rates of IVH and lower rates of surgery for PDA.

\section{DISCUSSION}

The main finding of our study is a survival advantage of preterm infants with a genetic background of elevated adult blood pressure. Many of the clinical factors which were associated with

Table 2 Effect size of clinical and genetic factors influencing measured lowest mean blood pressure in preterm infants on the first day of life

\begin{tabular}{|c|c|c|c|c|}
\hline Exposure & $\begin{array}{l}\text { Number of infants } \\
\text { exposed }\end{array}$ & $\begin{array}{l}\text { Lowest mean blood pressure on } \\
\text { day } 1 \text { in exposed infants }(\mathrm{mm} \mathrm{Hg}) \\
\text { mean } \pm \text { SD }\end{array}$ & $\begin{array}{l}\text { Effect size in linear } \\
\text { regression analysis } \\
(\mathrm{mm} \mathrm{Hg})(95 \% \mathrm{Cl})\end{array}$ & P value* \\
\hline All infants & 5380 & $27.7 \pm 6.3$ & n.a. & \\
\hline Higher gestational age (per week) & 5380 & n.a. & $+1.18(+1.10$ to +1.25$)$ & $<0.001$ \\
\hline Antenatal treatment with steroids & 4939 & $27.8 \pm 6.3$ & $+1.01(+0.47$ to +1.56$)$ & $<0.001$ \\
\hline Genetic score blood pressure (per cumulated beta-coefficient) & 5380 & n.a. & $+0.06(+0.01$ to +0.12$)$ & 0.032 \\
\hline APGAR score $<7$ at $5 \mathrm{~min}$ & 959 & $25.3 \pm 6.2$ & $-0.01(-0.41$ to +0.40$)$ & 0.967 \\
\hline Multiple birth & 1504 & $27.6 \pm 6.5$ & $-0.64(-0.96$ to -0.31$)$ & $<0.001$ \\
\hline Birth by emergency caesarean section & 571 & $26.0 \pm 5.9$ & $-0.87(-1.35$ to -0.39$)$ & $<0.001$ \\
\hline Mechanical ventilation on the first day of life & 2253 & $25.0 \pm 5.8$ & $-2.24(-2.58$ to -1.91$)$ & $<0.001$ \\
\hline
\end{tabular}

*Linear regression analysis was limited to 5380 infants due to missing data for APGAR score $(n=178)$ and emergency caesarean section $(n=24)$.

n.a., not available. 


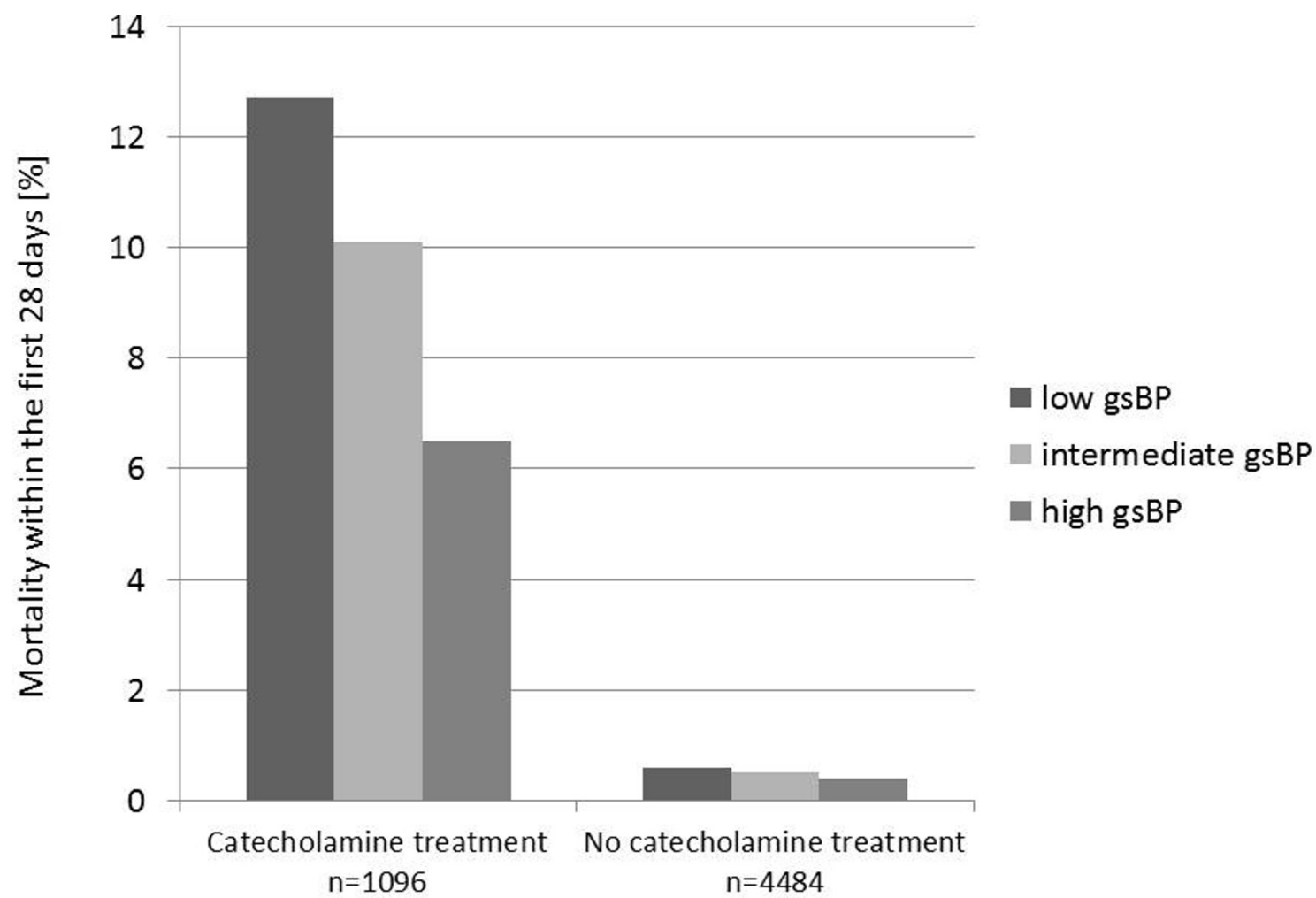

Figure 1 Mortality within the first 28 days of life stratified for genetic score blood pressure (gsBP) and treatment with catecholamines Treated infants: 28-day mortality, high vs low gsBP: $p=0.015$ (OR $0.48,95 \% \mathrm{Cl} 0.26$ to 0.87 ), Fisher's exact test.

blood pressure on the first day of life in our study have been reported previously. ${ }^{416}$ Due to the large size of our study, we were able to quantify the combined effects of these factors. These data should be helpful for clinicians who are uncertain if a preterm baby will need (eg, arterial umbilical) lines to monitor and treat low blood pressure.

In our cohort, infants with catecholamine therapy had higher mortality rates when compared with infants without catecholamine therapy, as also reported in other studies. ${ }^{2021}$ This might be due to confounding by indication, since drug treatment in our study was not randomised, for example, epinephrine is a standard drug for cardiopulmonary resuscitation. Within the subgroup of infants receiving catecholamine therapy, infants with high genetic blood pressure estimates had a 50\% lower mortality rate. This supports the view that genetic predisposition to high blood pressure has only moderate effects on resting blood pressure, but might be lifesaving by enhancing the response to catecholamine therapy in life-threatening situations.

Table 3 Logistic regression of 28-day mortality

\begin{tabular}{|c|c|c|c|c|}
\hline Exposure & Number of infants exposed & $\begin{array}{l}\text { Mortality in exposed } \\
\text { infants }(\%)\end{array}$ & $\begin{array}{l}\text { OR }(95 \% \mathrm{CI}) \text { for } 28 \text {-day } \\
\text { mortality in multivariate } \\
\text { logistic regression analysis }\end{array}$ & P value* \\
\hline All infants & 5380 & 2.4 & n.a. & n.a. \\
\hline Higher gestational age (per week) & 5380 & n.a. & $0.81(0.73$ to 0.90$)$ & $<0.001$ \\
\hline Antenatal treatment with steroids & 4939 & 2.2 & $0.66(0.38$ to 1.17$)$ & 0.15 \\
\hline $\begin{array}{l}\text { Measured lowest mean blood pressure on day } 1 \text { (per } \\
\text { additional } \mathrm{mm} \mathrm{Hg} \text { ) }\end{array}$ & 5380 & n.a. & 0.96 (0.92 to 0.998$)$ & 0.038 \\
\hline Genetic score blood pressure >P75 & 1340 & 1.6 & Ref. & Ref. \\
\hline Genetic score blood pressure P25-P75 & 2689 & 2.4 & $1.55(0.90$ to 2.68$)$ & 0.11 \\
\hline Genetic score blood pressure $<$ P25 & 1351 & 3.2 & 2.10 (1.18 to 3.74$)$ & 0.012 \\
\hline APGAR score $<7$ at 5 min & 959 & 5.3 & $1.36(0.89$ to 2.06$)$ & 0.15 \\
\hline Multiple birth & 1504 & 2.9 & 1.55 (1.02 to 2.35$)$ & 0.039 \\
\hline Birth by emergency caesarean section & 571 & 4.0 & $1.34(0.79$ to 2.29$)$ & 0.28 \\
\hline Mechanical ventilation on the first day of life & 2253 & 4.6 & $1.64(0.97$ to 2.76$)$ & 0.065 \\
\hline Dopamine & 512 & 8.4 & $0.98(0.62$ to 1.54$)$ & 0.92 \\
\hline Dobutamine & 595 & 9.9 & 1.83 (1.18 to 2.83$)$ & 0.007 \\
\hline Norepinephrine & 299 & 12.7 & 1.76 (1.08 to 2.88$)$ & 0.023 \\
\hline Epinephrine & 297 & 23.2 & $9.90(6.47$ to 15.1$)$ & $<0.001$ \\
\hline
\end{tabular}

n.a., not available. 
Table 4 Mortality and complications of premature birth stratified to genetic score blood pressure (gsBP)

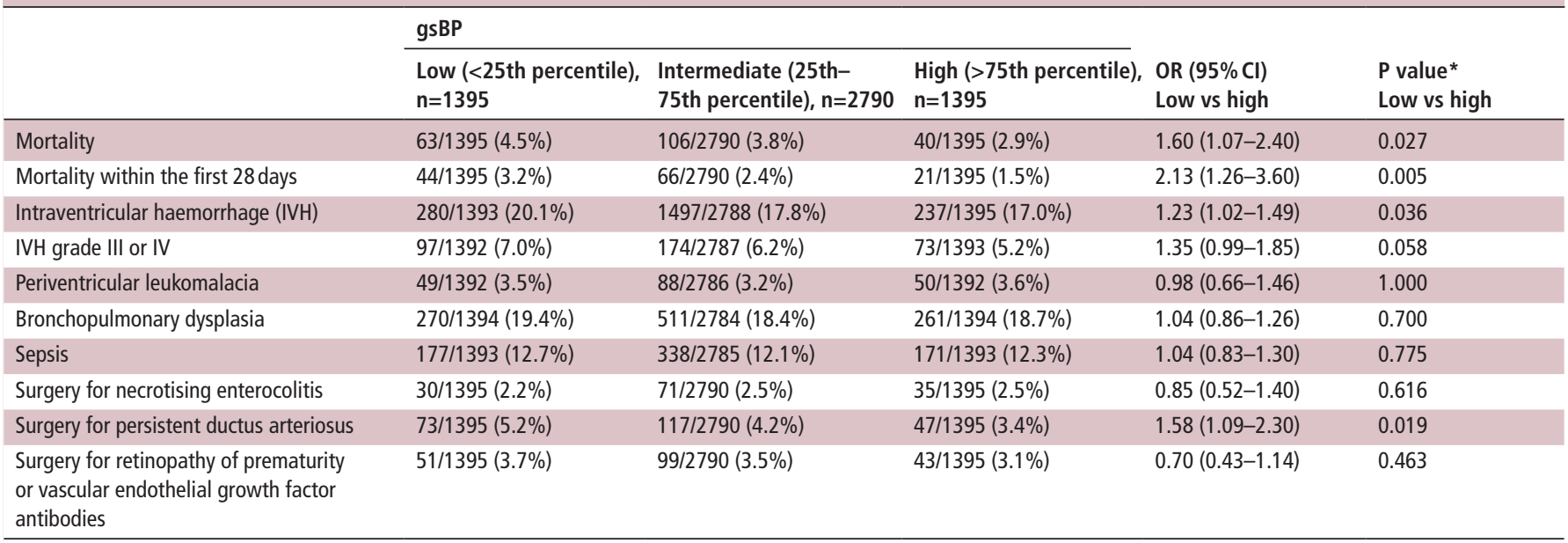

*Two-sided $p$ value comparing groups with low vs high gsBP. Fisher's exact test was used to compare variables.

Our data furthermore indicate that timing and dosage of current blood pressure treatment is not sufficient for all patients, and that a more personalised approach is needed.

Although inherited factors account for a substantial amount of blood pressure variance (and hypertension), it is still unclear why genetic predisposition for high blood pressure is so frequent in adults. ${ }^{22}$ Polymorphisms which were used for calculation and group assignment in our study were identified in a very large genome-wide association study involving $>200000$ adults of European descent. In adults, genotypes which are associated with high blood pressure are robust risk factors for negative outcomes including stroke and coronary artery disease. ${ }^{15}$ Current concepts assume that a genetic background of high blood pressure is a neutral factor at birth and during early childhood, but results in high incidence of death due to cardiovascular causes later in life. ${ }^{2324}$ Our data suggest that genetic traits for high blood pressure in adults are also associated with higher blood pressure in very premature infants. It is reasonable to assume that these traits are also associated with higher blood pressure in neonates, raising the question if they have been positively selected during human evolution because they are associated with lower death rates in infancy. ${ }^{25}$

In addition to lower mortality rates, infants with high gsBP had also lower rates of IVH, confirming previous reports that treatment of isolated hypotension might be helpful to reduce the burden of IVH. ${ }^{12}$

It must be emphasised that our data do not provide guidance with regard to intravenous volume therapy and catecholamine therapy itself. Although we observed substantial beneficial effects of genetic predisposition to high blood pressure, it is uncertain how effective blood pressure in preterm infants can be stabilised and if current treatment concepts (ie, early dopamine, dobutamine) have similar effects as genetic predisposition. These important questions can only be solved by adequately powered prospective randomised trials. ${ }^{26} 27$

Meta-analysis of late cord clamping, which increases intravascular volume after birth, demonstrated a reduced mortality rate in the treatment groups, ${ }^{17}$ although a large-scale randomised controlled trial did not find a significant difference for death or major morbidity. ${ }^{28}$ These data indicate that a sufficient volume therapy is very important for postnatal stabilisation of preterm infants. However, in the GNN most centres already practice either late cord clamping or cord milking. Despite this fact, infants with a predisposition for higher blood pressures had a survival advantage.

Our study has several limitations. Due to the minimal effect size of each polymorphism, the lack of systolic and diastolic blood pressure levels of infants and the much lower size of our cohort compared with adult datasets, we were not able to test the direct effects of single polymorphisms on blood pressure in preterm infants. This should be done with genome-wide association studies in preterm infants. Ideally, such studies will be able to analyse continuous blood pressure data and more endogenous exposures like cortisol levels and exogenous exposures like catecholamine dosing. This will hopefully result in identification of genetic variants with higher effect size and more specific scores which can be used for therapeutic decisions. Furthermore, our study only included infants of European descent and is therefore not generalisable to other populations. Although our results were unchanged if mothers with preeclampsia were excluded (data not shown), we were not able to test the effect of maternal hypertension, since maternal blood pressure data are not recorded in the GNN. Another limitation of our study is its focus on short-term outcomes. Genetically estimated blood pressure is a lifelong predisposition. Long-term outcome will be interesting, since the benefits of high estimated blood pressure with regard to such an important outcome measure like death suggest that long-term neurodevelopmental outcome of these infants might be superior as well.

Our data support causal protective effects of genetic determination to high blood pressure with regard to mortality in preterm infants. This effect was independent from catecholamine support and occurred within the first 4 weeks of life, suggesting that infants with a predisposition to low blood pressure might benefit from additional medications or altered treatment schedules (ie, personalised therapy). Long-term outcome data are pending. Future randomised controlled trials treating hypotension in preterm infants should consider the genetic predisposition of patients who are enrolled.

\footnotetext{
Author affiliations

${ }^{1}$ Paediatrics, University of Lübeck, Lübeck, Germany

${ }^{2}$ Neonatology, Brighton Sussex University Hospitals NHS Trust, Brighton, UK

${ }^{3}$ Institute for Medical Biometry and Statistics Lübeck, Lübeck, Germany

${ }^{4}$ Neonatology and Pediatric Intensive Care, University Hospital of Cologne, Cologne, Germany

${ }^{5}$ Department of Paediatrics, University of Cologne, Cologne, Germany
} 
${ }^{6}$ Institute of Clinical Molecular Biology, Christian-Albrechts-Universitat zu Kiel, Kiel, Germany

${ }^{7}$ Neonatology, Universitat Witten/Herdecke, Witten, Germany

${ }^{8}$ Neonatology, Semmelweis University, Budapest, Hungary

${ }^{9}$ Cologne Center for Genomics, University Hospital of Cologne, Cologne, Germany

${ }^{10}$ Division of Perinatal Reproductive Medicine, University of Liverpool, Liverpool, UK

Acknowledgements The authors would like to thank all participating patients, parents and physicians.

Contributors WG, MM, JB, KF, AK, JD, CH, CR and EH designed data collection tools, were responsible for the overall design of the study and patient enrolment. WG, TJ, DE, PN, AF and IRK were responsible for chip-genotyping, imputation and data analysis. WG, HR, MS, CH, MAT and EH were responsible for the analysis of clinical data. All authors contributed to the initial manuscript and revised the draft paper.

Funding This study was funded by the German Federal Ministry of Education and Research (GNN, BMBF 01ER0805 and BMBF 01ER1501) and European Union (NEOCIRC, FP7-282533).

Competing interests None declared.

Patient consent for publication Not required.

Ethics approval The German Neonatal Network study was approved by the ethics committee at the University of Lübeck and at each participating centre.

Provenance and peer review Not commissioned; externally peer reviewed.

Open access This is an open access article distributed in accordance with the Creative Commons Attribution Non Commercial (CC BY-NC 4.0) license, which permits others to distribute, remix, adapt, build upon this work non-commercially, and license their derivative works on different terms, provided the original work is properly cited, appropriate credit is given, any changes made indicated, and the use is non-commercial. See: http://creativecommons.org/licenses/by-nc/4.0/.

\section{ORCID iDs}

Heike Rabe http://orcid.org/0000-0002-2047-8875

Mark A Turner http://orcid.org/0000-0002-5299-8656

\section{REFERENCES}

1 Dionne JM, Abitbol CL, Flynn JT. Hypertension in infancy: diagnosis, management and outcome. Pediatr Nephrol 2012;27:17-32.

2 Barrington KJ, Janaillac M. Treating hypotension in extremely preterm infants. The pressure is mounting. Arch Dis Child Fetal Neonatal Ed 2016;101:F188-F189.

3 Batton B, Zhu X, Fanaroff J, et al. Blood pressure, anti-hypotensive therapy, and neurodevelopment in extremely preterm infants. J Pediatr 2009;154:351-7.

4 Faust K, Härtel C, Preuß M, et al. Short-term outcome of very-low-birthweight infants with arterial hypotension in the first $24 \mathrm{~h}$ of life. Arch Dis Child Fetal Neonatal Ed 2015:100:F388-F392.

5 Watkins AM, West CR, Cooke RW. Blood pressure and cerebral haemorrhage and ischaemia in very low birthweight infants. Early Hum Dev 1989:19:103-10.

6 Kuint J, Barak M, Morag I, et al. Early treated hypotension and outcome in very low birth weight infants. Neonatology 2009;95:311-6.

7 Dempsey EM, Al Hazzani F, Barrington KJ. Permissive hypotension in the extremely low birthweight infant with signs of good perfusion. Arch Dis Child Fetal Neonatal Ed 2009:94:F241-F244.
8 Batton B, Li L, Newman NS, et al. Early blood pressure, antihypotensive therapy and outcomes at 18-22 months' corrected age in extremely preterm infants. Arch Dis Child Fetal Neonatal Ed 2016;101:F201-F206.

9 Weindling AM. How has research in the last 5 years changed my clinical practice? Arch Dis Child Fetal Neonatal Ed 2010;95:F59-F63.

10 Dempsey EM. Challenges in Treating Low Blood Pressure in Preterm Infants. Children 2015;2:272-88.

11 Angus DC, van der Poll T. Severe sepsis and septic shock. N Engl J Med 2013;369:840-51.

12 Durrmeyer X, Marchand-Martin L, Porcher R, et al. Abstention or intervention for isolated hypotension in the first 3 days of life in extremely preterm infants: association with short-term outcomes in the EPIPAGE 2 cohort study. Arch Dis Child Fetal Neonatal Ed 2017:102:490-6.

13 Valverde E, Pellicer A, Madero R, et al. Dopamine versus epinephrine for cardiovascular support in low birth weight infants: analysis of systemic effects and neonatal clinical outcomes. Pediatrics 2006;117:e1213-e1222.

14 Barrington K, Brion LP. Dopamine versus no treatment to prevent renal dysfunction in indomethacin-treated preterm newborn infants. Cochrane Database Syst Rev 2002:3:CD003213.

15 Warren HR, Evangelou E, Cabrera CP, et al. Genome-wide association analysis identifies novel blood pressure loci and offers biological insights into cardiovascular risk. Nat Genet 2017;49:403-15.

16 Dempsey EM. What should we do about low blood pressure in preterm infants. Neonatology 2017:111:402-7.

17 Fogarty M, Osborn DA, Askie L, et al. Delayed vs early umbilical cord clamping for preterm infants: a systematic review and meta-analysis. Am J Obstet Gynecol 2018;218:1-18.

18 Voigt M, Rochow N, Guthmann F, et al. [Birth weight percentile values for girls and boys under consideration of maternal height]. $Z$ Geburtshilfe Neonatol 2012:216:212-9.

19 Papile LA, Burstein J, Burstein R, et al. Incidence and evolution of subependymal and intraventricular hemorrhage: a study of infants with birth weights less than $1,500 \mathrm{gm}$ J Pediatr 1978:92:529-34

20 Batton B, Li L, Newman NS, et al. Use of antihypotensive therapies in extremely preterm infants. Pediatrics 2013:131:e1865-e1873.

21 Fanaroff JM, Wilson-Costello DE, Newman NS, et al. Treated hypotension is associated with neonatal morbidity and hearing loss in extremely low birth weight infants. Pediatrics 2006;117:1131-5.

22 Muñoz M, Pong-Wong R, Canela-Xandri O, et al. Evaluating the contribution of genetics and familial shared environment to common disease using the UK Biobank. Nat Genet 2016:48:980-3.

23 Olsen MH, Angell SY, Asma S, et al. A call to action and a lifecourse strategy to address the global burden of raised blood pressure on current and future generations: the Lancet Commission on hypertension. Lancet 2016;388:2665-712.

24 Khera AV, Emdin CA, Drake I, et al. Genetic Risk, Adherence to a Healthy Lifestyle, and Coronary Disease. N Engl J Med 2016:375:2349-58.

25 Edwards MJ. Genetic selection of embryos that later develop the metabolic syndrome. Med Hypotheses 2012:78:621-5.

26 Mahoney L, Shah G, Crook D, et al. A Literature Review of the Pharmacokinetics and Pharmacodynamics of Dobutamine in Neonates. Pediatr Cardiol 2016;37:14-23.

27 Dempsey EM, Barrington KJ, Marlow N, et al. Management of hypotension in preterm infants (The HIP Trial): a randomised controlled trial of hypotension management in extremely low gestational age newborns. Neonatology 2014;105:275-81.

28 Tarnow-Mordi W, Morris J, Kirby A, et al. Delayed versus immediate cord clamping in preterm infants. N Engl J Med 2017:377:2445-55. 